\title{
Veno-venous extracorporeal membrane oxygenation with a bicaval dual-lumen catheter in a SynCardia total artificial heart patient
}

\author{
Sotirios Spiliopoulos*, Guenes Dogan, Dilek Guersoy, Maria Rosario Serrano, Reiner Koerfer and Gero Tenderich
}

\begin{abstract}
We report the case of a 55 years old caucasian male patient with cardiogenic shock due to an extended myocardial infarction who underwent SynCardia Total Artificial Heart implantation and veno-venous extracorporeal membrane oxygenation with a bicaval dual-lumen cannula for the treatment of adult respiratory distress syndrome.
\end{abstract}

Keywords: Circulatory assist devices, Acute respiratory distress syndrome, Extracorporeal membrane oxygenation

\section{Background}

Refractory cardiogenic schock can be associated with severe respiratory failure requiring extracorporeal membrane oxygenation. We report the first case of Adult respiratory Distress Syndrome in a Total Artificial Heart patient treated by veno-venous extracorporeal membrane oxygenation with a bicaval dual lumen cannula.

\section{Case presentation}

Refractory cardiogenic shock due to an extended myocardial infarction and biventricular heart failure is an established indication for the implantation of a Syn CardiaTotal Artificial Heart [1]. In cases of severe respiratory failure, extracorporeal membrane oxygenation may also become necessary [2]. Usually a dual-site venovenous or veno-arterial cannulation is then performed. We report the first case of adult respiratory distress syndrome in a SynCardia Total Artificial Heart patient which was successfully treated by veno-venous extracorporeal membrane oxygenation with a single-site bicaval duallumen catheter placed in the right internal jugular vein.

Angiography of a 55 years old caucasian male patient with an anterior ST segment-elevation myocardial infarction showed thrombosis of the left anterior descending artery and left main artery disease. Despite angioplasty and inotropic therapy the patient continued to decline. Veno-

\footnotetext{
*Correspondence: sotirios.spiliopolos@ejk.de

Department for the surgical therapy of end-stage heart failure and

mechanical circulatory support, Heart and Vascular Center Duisburg, 47169 Duisburg, Germany
}

(c) 2013 Spiliopoulos et al.; licensee BioMed Central Ltd. This is an Open Access article distributed under the terms of the Creative Commons Attribution License (http://creativecommons.org/licenses/by/2.0), which permits unrestricted use, distribution, and reproduction in any medium, provided the original work is properly cited. cessary. Radiology showed severe pulmonary congestion and edema due to cardiac decompensation. Additionally, aspiration during endotracheal intubation resulted into pneumonia and severe pulmonary failure causing an adult respiratory distress syndrome with a severe defect in oxygenation and decreased lung compliance. Prior to the procedure high minute ventilation was required to attain normal $\mathrm{PaCO} 2$ levels. The veno-arterial ECMO was explanted and implantation of the SynCardia Total Artificial Heart (SynCardia Systems, Inc, Tucson Arizona, USA) was performed as described above [3]. The patient was weaned from extracorporeal circulation and the Total Artificial Heart took over circulation. Due to pre-existent respiratory failure we decided to implement veno-venous extracorporeal membrane oxygenation (Levitronix Centrimag, Switzerland). The circuit was connected to a $19 \mathrm{~F}$ bicaval dual-lumen cannula (Avalon Elite, Maquet Cardiovascular, Germany) placed in the right internal jugular vein as previously described [4]. Correct placement of the cannula in the inferior vena cava and the right atrium was ensured by transesophageal echocardiography. Due to a coagulation disorder and excessive bleeding, the sternum was initially left open and the patient was brought to the ward. Anticoagulation with heparin was instituted 24 hours later with a target-partial thromboplastin time of 60 seconds. Under ECMO support, antibiotics and fluid-conservative management, the adult respiratory distress syndrome gradually resolved. Total duration of ECMO support was 191 hours. ECMO pump flow ranged between 3,0 and 
4,0 L/min with TAH cardiac output ranging between 5,1 and 7,7 L/min for the left and 4,2 and 7,3 L/min for the right artificial ventricle. The bicaval dual-lumen cannula was surgically removed. Initially the patient recovered fully and left the ward, but he unfortunately died at postoperative day 192 due to a sepsis related to a driveline-infection.

\section{Conclusions}

Adult respiratory syndrome is a critical condition with a reported in-hospital mortality of $57.9 \%$ [5]. Current therapy includes fluid restriction and volume-controlled ventilation with low tidal-volumes and low plateau pressure levels [6]. Extracorporeal membrane oxygenation is known to be associated with a significant survival benefit [7] However although there have been numerous reports on extracorporeal membrane oxygenation and ARDS in general, the parallel application of an ECMO and the SynCardia Total Artificial Heart for the treatment of severe respiratory failure has been reported once [2]. In our case respiratory failure resulted from cardiogenic shock and aspiration during endotracheal intubation and did not resume despite preoperative veno-arterial ECMO-therapy. Therefore we had to assume a prolonged postoperative duration of ECMO-support. In this context single-site veno-venous cannulation proved to have numerous advantages: it is simple to perform, it minimizes the risk of cannula dislodgement during patient care, reduces the risk of catheter related infections and finally allows early sternum closure. Single-site venous cannulation could be a reasonable alternative to conventional cannulation for ECMOsupport in SynCardia Total Artificial Heart patients with an adult respiratory distress syndrome.

\section{Consent}

The patient has given his consent for the case report to be published.

\section{Competing interests}

The authors declare that they have no competing interests.

\section{Authors' contributions}

SS drafted the manuscript. GD was involved in the drafting of the manuscript. DG was involved in the drafting of the manuscript. MRS revised the manuscript. RK has given final approval of the version to be published. GT has given final approval of the version to be published. All authors read and approved the final manuscript

Received: 10 May 2013 Accepted: 29 July 2013

Published: 5 August 2013

\section{References}

1. Morshuis M, Reiss N, Arusoglu L, Tenderich G, Koerfer R, El-Banayosi A: Implantation of CardioWest Total Artificial Heart for irreversible acute myocardial infarction. Heart Surg Forum 2007, 10(4):251-25.

2. Anderson E, Jaroszewski D, Pierce C, DeValeria P, Arabia F: Parallel application of extracorporeal membrane oxygenation an the CardioWest Total Artificial Heart as a bridge to transplant. Ann Thorac Surg 2009, 88:1676-1678
3. Koerfer R, El-Banayosy A, Morshuis M, Tenderich G, Reiss N, Arusoglu L: Total artificial heart-implantation technique using the CardioWest or the Thoratec system. MMCTS 2007, 0329:2006.002485.

4. Javidfar J, Brodie D, Wang D, Ibrahimiye AN, et al: Use of bicaval duallumen catheter for adult veno-venous extracorporeal membrane oxygenation. Ann Thorac Surg 2011, 91(6):1763-1769.

5. Brun-Buisson C, Minelli C, Bertolini G, Brazi L, et al: Epidemiology and outcome of acute lung injury in European intensive care units. Results from the ALIVE study. Intensive Care Med 2004, 30:51-61.

6. The National Heart, Lung and Blood Institute ARDS Clinical trials network: Higher versus lower positive end-expiratory pressures in patients with the acute respiratory distress syndrome. N Eng J Med 2004, 351:327-336.

7. Peek J, Mugford M, Tiruvoipati R, Wilson A, et al: Efficacy and economic assessment of conventional ventilator support versus ECMO for severe adult respiratory failure (CESAR): a multi-center randomized control trial. Lancet 2009, 374:1351-1363.

doi:10.1186/1749-8090-8-179

Cite this article as: Spiliopoulos et al: Veno-venous extracorporeal membrane oxygenation with a bicaval dual-lumen catheter in a SynCardia total artificial heart patient. Journal of Cardiothoracic Surgery 2013 8:179

\section{Submit your next manuscript to BioMed Central and take full advantage of:}

- Convenient online submission

- Thorough peer review

- No space constraints or color figure charges

- Immediate publication on acceptance

- Inclusion in PubMed, CAS, Scopus and Google Scholar

- Research which is freely available for redistribution 